\title{
Introduction: Epistemic and Artistic List-Making
}

\author{
Roman Alexander Barton, Julia Böckling, Sarah Link, \\ and Anne Rüggemeier
}

The etymology of the term list reveals more about the nature of the thing itself than is commonly acknowledged. ${ }^{1}$ Derived from the Old High German lista and the Old English liste, the word originally designated a small strip of cloth, a hem, a piece of braid, or border. Its first metaphorical use appears to have been due to its synonymity with border: until early modern times, lists could signify land borders. ${ }^{2}$ More groundbreaking of course was the term's application to the field of writing and literature, an association that was perhaps to be expected given the traditional semantic proximity of text and textile, both derivatives of the Latin texere. The word list, then, more so than other related terms such as enumeration or

\footnotetext{
This introduction is the outcome of our joint research conducted in the project Lists in Literature and Culture (LISTLIT), funded by the European Research Council Starting Grant no. 715021
}

R. A. Barton $(\bowtie) \bullet J$. Böckling $\bullet S$. Link $\bullet$ A. Rüggemeier University of Freiburg, Freiburg, Germany e-mail: roman.barton@anglistik.uni-freiburg.de; salink@uni-wuppertal.de; anne.rueggemeier@anglistik.uni-freiburg.de

(C) The Author(s) 2022

R. A. Barton et al. (eds.), Forms of List-Making: Epistemic, Literary, and Visual Enumeration, https://doi.org/10.1007/978-3-030-76970-3_1 
catalogue, carries the denotation of handiwork. It implies a made product or, more precisely, a subproduct in bigger textile or textual endeavors. When the proximity of text and textile is made explicit in literary works of the Middle Ages, authors appear to reflect on their "wordweaving," the poiesis of literature. ${ }^{3}$ Accordingly, the term list puts stress on the making of enumerative texts and their contents. It invites us to reflect on how art or knowledge is produced through enumeration. With this edited volume, we have accepted that invitation and brought together scholars from various disciplines to explore list-making as a means of epistemic and artistic creation.

Perhaps the most striking similarity between a strip of cloth and a textual enumeration, and thus perchance the ground of their etymological connection, is their shared appearance or form. Though this form is easily recognizable, scholars have found it difficult to pin down and indeed are undecided whether it is a graphic or a grammatical structure. Theorizing the form of the textual list is very challenging because, as many have pointed out, versatility is its most remarkable feature. ${ }^{4}$ In the emerging field of list studies, the list's form as well as its pivotal functions continue to be debated or renegotiated as more and more specific contexts of enumeration are taken into account. Moreover, lists are elusive: although they have classified, organized, and categorized the world since the early high civilizations,${ }^{5}$ they also, and sometimes simultaneously, have shown a tendency to confuse and overwhelm their readers. This tendency is perhaps best captured in the much-cited fictional taxonomy of animals by Jorge Luis Borges, supposedly of ancient Chinese origin, which is both intentionally unintelligible and evidently playful. ${ }^{6}$ What Borges' example suggests, among other things, is that the list, however elusive, has been a mainstay in both epistemic and artistic endeavors since ancient times. In spite of this, the list has received, until recently, little or no attention in histories of knowledge, literature, or the visual arts.

The past decade or so has seen a growing interest in the role that lists play in knowledge-making, an interest that could possibly be explained by the prominence of enumerative structures in contemporary digital formats. Part I of our book seeks to contribute to the current debate by examining the epistemic functions of the list in a diachronic perspective. Most previous research on the subject is based on the assertion that, because list-making originates in administration, administrative textual practices have defined the scientific list ever since. ${ }^{7}$ This view has prompted invaluable studies on the often underestimated politics of the list, the 
invisible power structures that define the selection and arrangement of a list's contents in governance and beyond. ${ }^{8}$ The first section of this volume pursues a different approach in that it points out the impact of some of the other genres traditionally associated with list-making as a means of knowledge-making, namely historiography, wisdom literature, natural history, and the character sketch. By providing new case studies, it continues the work performed in Lucie Doležalová's edited volume The Charm of a List: From the Sumerians to Computerised Data Processing (2009) and Liam Cole Young's monograph List Cultures: Knowledge and Poetics from Mesopotamia to BuzzFeed (2017), two attempts to think about the allure of lists in different fields of knowledge. Though we agree with these authors that the list is and has always been an indispensable cognitive tool that helps to manage (big) data, we wish to encourage further research on the long and eventful epistemic history of the list: to what extent has scientific list-making been subject to epistemological shifts throughout history?

Like the scientific list, the literary list has lately become a "hot topic," and the second part of this book acknowledges as much. While the epic catalogue has been a subject of research in classical philology for quite some time, ${ }^{9}$ the list as a literary form was taken seriously only after the turn of the millennium. Nor has the related concept of enumeratio, which originates in ancient rhetoric, received much scholarly attention until the past few years. ${ }^{10}$ In fact, rhetorical and hence much poetological knowledge about enumeration has been handed down the centuries more or less unchanged (Schöpsdau 1994). Reflections on the enumerative in literature have gained currency only since the publication of Sabine Mainberger's pioneering monograph Die Kunst des Aufzüblens: Elemente zu einer Poetik des Enumerativen (2003), which presents a multifaceted overview of the mutability and manifold functions of literary enumeration. ${ }^{11}$ Subsequently, a range of more detailed and specific studies on the subject, which cover individual works or epochs, have appeared in print. Terminologically speaking, they all favor the more neutral and inclusive designation list over the more specifically rhetorical term enumeration. ${ }^{12}$ Perhaps most notably, Robert Belknap's monograph The List: The Uses and Pleasures of Cataloguing (2004) discusses lists in the works of four prominent American Renaissance authors, namely Emerson, Whitman, Melville, and Thoreau, as well as across different genres. ${ }^{13}$ Taking a broader diachronic approach, Eva von Contzen has called for a "listory," that is, "a literary history of lists" $(2016,241)$ as well as an investigation of the relationship 
of narration and enumeration. Her edited special issue for the journal Style brings together a group of narratologists to explore literary list-making throughout the centuries. The distinctive tension between the list and the narrative here examined is also taken up in a recent issue on "Lists and Narrative" (Literatur in Wissenschaft und Unterricht 1:2 2020), which highlights the multidirectional potential of the list both as a literary and a socio-cultural form. Part II of our book continues this work and, in so doing, follows Caroline Levine's Forms: Whole, Rhythm, Hierarchy, Network (2015) in its conviction that form is not only a rewarding focus for the study of literature but also for the study of culture and that an examination of formal features can produce insights into socio-cultural contexts.

Building on the supposition that the list is not only a grammatical but also (and perhaps even more so) a graphic structure, the third and final part of this edited volume explores the role of lists in the visual arts. It thus takes up an argument first presented in one of the most widely cited publications on list-making, Umberto Eco's The Infinity of Lists (2009). This anthology, which emerged from a series of conferences and exhibitions that Eco organized at the Musée de Louvre, draws attention to the challenging and multifarious richness of the list in literature and painting. Perhaps the most intriguing question that the book raises is whether or not there is such a thing as the "visual list," a term that is introduced with disarming naturalness and yet remains suspiciously under-theorized. The present volume investigates visual list-making in the domains of book illustration, painting, and photography in an attempt to stimulate further research on the topic.

In summary, List-Making: Epistemic, Literary, and Visual Enumeration brings together scholars from various academic fields to critically review previous list research and examine further how lists enabled the production of scientific, literary, and art work throughout the ages. The twelve single-authored chapters place the list in different well-researched historical contexts to fully grasp the epistemic, poetic, and aesthetic needs or potentialities that it can express and afford.

\section{(List-)Making KnOWLedge}

The versatile form of the list is central to knowledge-making in that it records, stores, and communicates various kinds of intelligence. Although the list is ever-present in scientific literature from antiquity to the present, 
it has rarely attracted the interest of intellectual historians. Only in more recent times, which have witnessed the advancement of digital networking and the prominence of enumerative structures in social media formats, a special urgency for research into the epistemic practice of enumeration has been recognized. As information circulates with ever-greater speed in the digital age, list-making, perhaps the most time-efficient means of processing intelligence, is recognized not as an inferior but a pivotal means of producing knowledge. ${ }^{14}$

Pointing out the longue durée of the list, many have suggested that enumeration is a universal concept or, at the very least, an anthropological constant. ${ }^{15}$ Though it is fascinating that lists were apparently as prominent in ancient Mesopotamia as they are today, as suggested by Liam Cole Young (2017), it does not follow that enumeration is an invariable concept or form. As research on the role of paper and pen in the production of knowledge has revealed, the (early) modern period witnessed significant revolutions in paper technology that, as a result, revolutionized listmaking. ${ }^{16}$ Also, when seen from an epistemological perspective, the list appears to transform throughout the centuries. Considered as a cognitive tool that responds to epistemological shifts, the list reveals profound changes in the ways of thinking and knowing.

The aim of the first part of this book is to highlight the list's longstanding epistemic history. Chapters 2, 3, 4 and 5 work toward an understanding of the list as an epistemic tool that connects various contexts and evolves across centuries. Rather than treating the list solely as a literary or a rhetorical form, a manner of composition and arrangement in various kinds of literature, the four authors acknowledge that it is furthermore (and often at the same time) a cognitive tool which affords intellectual activity, a claim first made by Jack Goody (1977). ${ }^{17}$ However, and this Goody paid no attention to, the list as a cognitive tool transforms, just as the epistemes themselves are subject to gradual but significant change. Traditionally, of course, the term epistēme has been contrasted with that of techne to distinguish immutable theoretical knowledge from empirical insight that develops over time. ${ }^{18}$ Epistemes are not mere deductions from experience but the conditions under which humans create empirical knowledge in the first place. At least since the emergence of discourse studies, however, epistemes are no longer considered as fixed, but in flux. In The Order of Things (1980), a work which famously commences with the discussion of a list, namely the aforementioned Chinese taxonomy of Borges, Michel Foucault has argued that epistemes are the ground of and 
prior to discourse. ${ }^{19}$ They signify historically specific ways of knowing, "apparatuses" with which to distinguish what counts as valid from what counts as invalid in a certain field at a particular point in time. Notably, for Foucault, not only human knowledge itself but the conditions of knowing are prone to historical change. Both what we know and how we know differs throughout the ages. As they are thus subject to transformation, epistemes define and redefine how knowledge is made, not least in the textual list.

The list could thus perhaps be understood as an evolving "epistemic genre" much like the question or the case. ${ }^{20}$ As recent scholarship has shown, these are modes of thinking which employ a specific recognizable pattern and, in so doing, raise discursive validity claims that are historically specific. It seems that the list with its itemizing pattern is just such a mode. The notion of "epistemic genre" as defined by Gianna Pomata and others is certainly not without its pitfalls. In the instance of the case, for example, it somewhat obscures the specific origin of the genre in administrative paperwork. The list, however, is much more ubiquitous; it already played an important role in so many contexts in antiquity that this consideration is not an issue. More problematically, perhaps, theorizing the list as an epistemic genre could blur differences and suggest that, for example, an exegetical list and a botanical list are more similar than they really are. To remedy this potential fallacy, our book brings together specialists from various academic fields who place the respective lists in well-researched contexts. Telling part of the epistemic history of the list, the first four chapters demonstrate how enumeration enabled intellectual work in classical historiography, ancient and medieval wisdom literature, early modern moral weeklies, and nineteenth-century botanical geography.

In Chap. 2, Martin Stöckinger shows that lists allowed Roman imperial and early medieval historians to give a complete but contingent record of dates, events, or persons of the past. Taking the list of the Res Gestae Divi Augusti as example, he argues that, rather than establishing causalities, imperial lists are a "monument" of an Emperor's achievements. Due to their dignity, these enumerations cannot be expanded or otherwise altered and, because of their great length, they also convey a sense of magnitude: no other list can compare. By contrast, lists in Gregory of Tour's Historia Francorum transform previous enumerations and are open to continuation. Thus, the cognitive tool of the list enabled pre-modern historiographers to either finalize the record of a specific past or chronicle the progress 
of time. In other words, both their summative and their additive intellectual work relied on the epistemic practice of list-making.

In Chap. 3, Lennart Lehmhaus puts into perspective the traditional view that scholarship in the ancient Near East was inferior to GrecoRoman schools of thought because of its tendency to produce (mere) lists. The Rabbinic lists, he argues, had important epistemological functions. In ancient Talmudic texts, they are used to appropriate, transmit, and create medical or moral knowledge. By affording recipes and regimens, the epistemic form of the list enabled the rabbis to instruct on how to lead a healthy way of life. Meanwhile, in midrashic works, the list is key to theological exegesis and is thus a powerful hermeneutic tool. As such, it impacts the cognitive act of understanding itself. Crucially, the Rabbinic lists come to be expanded, shortened, or rearranged. They are open to continuation and thus open to new hermeneutic endeavors.

Chapter 4 argues that in the periodicals of Joseph Addison and Richard Steele, the Tatler and the Spectator, lists such as the virtuoso's testament and Leonora's library catalogue enumerate the possessions of a certain character type, thus revealing the owner's moral deficiencies. Theresa Schön demonstrates that, as they lack apparent order, such enumerations give form to what appear to be chance empirical observations. They imply a survey of the reader's bookshelves or the contents of a virtuoso's house, respectively. Consequently, these lists allow the reader to make moral deductions as if from experience. Due to their overt experiential quality, the lists of Addison and Steele make new the well-known and established typology behind the character sketch, a genre which harks back to antiquity. They do so in that they signal "the (technically) infinite nature of observation" (Schön). Thus, these eighteenth-century lists reveal the impact of Empiricism on the list-making of knowledge.

Focusing on Alexander von Humboldt's American Travel Journals, Chap. 5 discusses how the scientific list took on new functions in the wake of a paradigm shift in the history of knowledge around 1800. Ottmar Ette shows that Humboldt's list-making shaped and was shaped by his novel trans-areal as well as trans-scalar conception of science. Rather than composing static taxonomies, his lists make reference to geographies of natural entities, showing their evolution or migration. The list, now considered as necessarily infinite, emerges as an ideal tool to showcase scientific study as a quintessentially nomadic process that is never completed or flawless, much in contrast to traditional monadic science. Often combined into 
tables to represent the multi-relationality of natural life, Humboldt's lists are thus strategically incomplete and inconsistent.

In summary, Part I of this book points out basic epistemic functions of enumeration, that is, the role of lists in summative, additive, didactic, and hermeneutic endeavors, yet it also points to certain shifts in the epistemic history of the list. In particular, the case studies suggest that the emergence of Empiricism and Evolutionism had a remarkable impact on enumerative knowledge-making, an issue that deserves further comment not least because it touches on two commonplaces in list research. From an epistemological perspective, both the assertion that lists are closely related to the concept of infinity and the claim that they easily combine into tables to represent multi-relationality merits greater attention.

First, the conviction that all knowledge is gained from experience seems to have produced the insight that (empirical) lists are necessarily infinite. Arguing against Jack Goody (1977), for whom the list with its classificatory tendency "establishes the necessity of a boundary, the necessity of a beginning and an end" (105), Umberto Eco famously claimed that the list in general is a "form of representation" which "suggests infinity almost physically, because in fact it does not end, nor does it conclude in form" (Eco 2009, 17). However, his assertion that lists not only convey the notion of infinity by aesthetic means but are also and have always been logically infinite is a bit of a stretch. ${ }^{21}$ The dilemma that enumeration can neither encompass nor represent everything or, more precisely, everything in sufficient empirical detail, and therefore must progress ad infinitum, is distinctly modern. Only in the eyes of the empiricist, who came to dominate the scientific field in the eighteenth century, no finite list is ever enough. ${ }^{22}$

Second, it is remarkable how the making of modern life sciences has resulted in the understanding that the list, considered as the outcome of additive intellectual work to be continued ad infinitum, is necessarily interrelated with other lists. As Alexander von Humboldt's example shows and recent research on tabular tallying in nineteenth-century medicine implies ${ }^{23}$ scientific lists come to serve as hermeneutic tools for one another and thus become mutually productive. This is highly significant because, speaking with the logician Charles Sanders Peirce, the list is dyadic. An enumeration of the items $\mathrm{A}, \mathrm{B}, \mathrm{C}$, and $\mathrm{D}$ signifies no more than that $\mathrm{A}$ is related to $\mathrm{B}, \mathrm{B}$ is related to $\mathrm{C}$, and $\mathrm{C}$ is related to $\mathrm{D}$. In other words, any list is composed only of dyads. The medium between the list's items, the answer to the question what connects them (for instance, their all being 
trees), no list can make explicit in and of itself. In the words of Peirce, the list lacks thirdness because it features only relates and correlates, but no interpretant. ${ }^{24}$ Unless the enumeration has a title (such as "Trees") or is embedded in a narrative that interprets it, the logic of the list remains in the dark. A science (only) of lists remedies this logical insufficiency in that it asserts the necessary interaction of scientific enumerations. One list supplies another with an interpretant and so the transformation of one or both of these lists is the likely result. For instance, to put it very simply, a taxonomy of plants can be a tool with which to interpret a list of trees, namely because it includes the item "tree." As a result, a normative title or narrative becomes obsolete. Thus, perhaps for the first time in Western civilization, the mere combination of lists (and flawed or incoherent lists especially) is acknowledged as a sufficient means of knowledge-making. Further research on how scientific list-making came to be characterized by multi-relationality is needed and, with this edited volume, we hope to encourage it.

\section{Lists Versus NarRatives}

“One does not read but only uses a list” $(2009,1)$ writes Lucie Doležalová in her introduction to The Charm of a List and thus situates enumeration firmly in the realm of functionality rather than that of literature. It is, however, the list's very usability that qualifies it as a cognitive tool which invites its users to order and link its constituent items, to examine which connections can be drawn between them, and to determine how they relate to one another or the larger framework in which they are presented. (Certainly, in some cases, lists may want the user to blindly accept the connections they imply.) Nevertheless, lists and narratives are commonly regarded as contraries: while the latter are based on sequential or causal relationships and establish meaningful connections, the former are characterized by itemization or computationality. Insofar as they are a phenomenon pertaining to the descriptive or the argumentative mode of writing, lists can be conceptualized as "anti-narrative" texts. One could even argue that lists, "as inherently nonnarrative elements, constitute 'the Other' in a literary work" (von Contzen 2016, 245). However, lists have the potential to be transformed into narratives when readers interact with them. This transformative potential suggests that lists and narratives are not diametrically opposed to one another. Rather, as the contributions to Part II of this book demonstrate, there are degrees of narrativity which can be realized 
more or less fully in the list: enumerative texts can acquire a somewhat narrative quality.

Placing enumerative texts on a sliding scale between narrative and nonnarrative corresponds with Robert Belknap's definition of lists as frameworks "that hold separate and disparate items together" $(2004,2)$. Lists, somewhat like narratives, allow us "to order our surrounding world, verbally or symbolically putting everything into a sequence and an arrangement we desire" (Belknap 2004, xxii). It becomes obvious that the realms of enumeration and narrative are not as clearly separable as they initially seem. However, while lists produce order primarily through their form, narratives tend to join items by causal concatenation. More so than narratives, lists draw attention to their own constructedness and thereby make transparent how order can be created. Such transparency endows lists with the potential to explode or subvert established ordering systems by laying bare and then reimagining the structures upon which they are based. Chapters 6, 7, 8, 9 and 10 examine how the connections that lists invite their readers to draw between item and item or item and formal framework create a tension between enumeration and narrative. This tension, which lists in a literary context almost inevitably create, renders them productive in a variety of ways. Lists thus address issues such as canonformation and counter-culture.

The invisible political agenda behind lists-the so-called politics of the list-is the topic of Eva von Contzen's contribution (Chap. 6). She explores the list as a cognitive form which elicits a range of affordances that vary according to the context they are used in. Von Contzen suggests that lists should be read symptomatically and suspiciously. Drawing on lists and catalogues in works as diverse as Daniel Defoe's Robinson Crusoe and Leanne Shapton's Important Artifacts and Personal Property from the Collection of Lenore Doolan and Harold Morris, she unmasks the capitalist narratives that are intricately interwoven with these texts. Underneath the surface of the list, von Contzen argues, there is "potentially an abyss of contradiction and manipulation."

Chapter 7 explores how, without actually having to narrate, lists imply certain narratives. Stefanie Lethbridge illustrates this phenomenon by examining the table or list of contents in the context of canon formation. ${ }^{25}$ She demonstrates how British poetry anthologies make use of the form of the list to create epistemic, cognitive, and affective frames that govern the reception of literature. Through sequence and proximity, and through intertextual connections and resonances, these frames influence whether a 
poem will be read as a work by a certain author or else as a typical example of a literary period, theme, or mood. Remarkably, tables of contents thus elicit a narrative response by capitalizing on the "human predilection for creating teleological connections" (Lethbridge).

That both list-making and storytelling assert and establish authority has become clear in recent debates about the role of narratives in political discourse. De Goede et al. (2016) and Stäheli (2016) have convincingly argued for the invisible power that governs the politics of the list. However, lists do not only solidify but also destabilize political power. Alyson Brickey illustrates this in her discussion of enumeration in Allen Ginsberg's "Howl." (Chap. 8) The speaker uses the form of the list to break with continuous narration and foreground the poem's a-narrative character. The feelings of alienation and "aesthetic unrest" thus created combat established (and potentially oppressive) power structures. Brickey's reading of "Howl" demonstrates how the poem not only inextricably links the form of the list to questions of ethics but itself performs ethical work. As a Beat Generation poem, "Howl" is firmly rooted in counter-culture and is generally read as a response to an increasingly conservative American cultural sphere after the Second World War.

The subversive potential of the list also features prominently in Juri Joensuu's discussion of twentieth-century Finnish recipe poems. In Chap. 9, Joensuu emphasizes how lists both unify and fragment the (textual) spaces they create. By employing the rigid and traditional form of the recipe or menu to present scandalous or deliberately alienating content, these poems demonstrate a refusal to conform to established literary and societal norms. In the processual context of recipe writing, the list form evokes connotations of order, sterility, and objectivity that clash with the recipe poems' contents which center around sensuality, (sexual) taboo topics, and disgust. The list thus creates a shock effect that constitutes a deliberate attack on established (aesthetic) norms and values.

While Brickey and Joensuu shed light on the list's propensity to be used in counter-cultural art and discourse, Ulrike Vedder's contribution explores the self-reflexive potential and embodied nature of poetological lists (Chap. 10). The lists Vedder examines draw attention to their own constructedness by highlighting the processual nature of writing. Through their loose connections and fragmentariness, lists evoke the impression of spontaneity or immediacy. Vedder demonstrates this across a variety of genres. For example, turning to a poem by Inger Christensen, she shows how the order that lists establish can constitute an act of creation. 
Furthermore, in her reading of Jack Kerouac's manifesto Belief \& Technique for Modern Prose, Vedder points out the unique temporality of lists. Finally, she theorizes the literary list in her discussion of roland BARTHES par roland barthes (1975), which explores fragmentation as a form of narration.

In summary, Part II of this book addresses the ability of the list to challenge both our notion of narrative and the grand narratives of our culture. ${ }^{26}$ The four contributions show that the tension between enumeration and narrative often evokes a "desire for creative disruption" (Richardson 2016, 328): literary lists twist conceptions of order in that they take shapes which expose their constructedness. They scrutinize established ways of sense-making and thereby invite the reader to question the power structures that underpin dominant cultural narratives.

\section{The Visual LisT}

The third and final part of this book is dedicated to a specific research desideratum in list studies. Despite its visual quality, that is, its typographically specific, often framed, and vertical layout, we associate the form of the list, first and foremost, with a verbal, written, or even printed form of publication. ${ }^{27}$ Yet there are no convincing reasons why a succession of written objects should be called a list, while a series of shown-that is, drawn or photographed-objects should not. The very basic definition of the list as "a structural schema of enumeration in which particular items [...] are arranged in a series" (Fludernik 2016, 309) can be applied to both the verbal and the visual list. ${ }^{28}$

$\mathrm{EcO}$, in his fascinating and widely cited The Infinity of Lists, shows the current relevance of the topic. Eco refers to both poets and writers who use lists in their literary works and painters who accumulate things in their paintings. As he invents a language for what he conceives as the essential nature of lists, he describes the oscillation between completeness and infinity, that is, between form and delimitation of form, as essential (Eco $2009,7)$. If Eco's lists are defined at all, then this is done only with regard to their effect, but never by describing their formal characteristics. Moreover, Eco reduces the definition of the visual list to only one of its effects, its suggestion of an etcetera: "how [can] a picture [...] present things and yet suggest an 'etcetera' as if to admit that the limits of the 
frame oblige the picture to say nothing about an immense number of other things" (Eco 2009, Introduction).

It seems that Eco's very cover image, a detail from Sir Edward Coley Burn-Jones' The Golden Stairs (1880)—which is not mentioned once in the rest of the book- has the potential to develop a set of formal criteria that can be seen as responsible for its "effet de liste" (see Milcent-Lawson et al. 2013). We see a sequence of women dressed in creamy white, silvery antique robes, as they descend a staircase. The vertical arrangement of the canvas is decisive for its list effect. The eye of the observer wanders downward, literally following the long parade of somewhat identical women step by step (the feet are visible despite the long robes). In terms of hairstyle, skin color, and clothing, they resemble each other, thus creating the impression of repetition in variation, ${ }^{29}$ a characteristic pattern, which in art history-but also in literature and media studies-has thus far primarily been designated with the term series. The list and the series are united by their reflexive function: they evoke an emphasis on and thus a reflection of the how of representation as opposed to a simple focus on the what of representation. While the visual series as a primarily aesthetic form demands the consistent application (or further development) of certain pictorial and design rules, the visual list as a form-perhaps precisely because the term has no tradition in visual art-is less prescriptive. In contrast to the series, where the individual objects must always be related to each other semantically, the connection between the individual elements of a list can be established solely through their belonging to a shared whole.

As a form that transcends context, the list can manifest in visual art in variable ways. The list affords a "unifying gesture" that helps to visually organize the multiplicity of singular or rather singularized (i.e., previously decontextualized, cut, or consciously selected) elements. This "unifying gesture" could be a title, or some framing effect, or simply the (material or mental) meeting place of the list: for example, a canvas, a page, a spontaneously torn off piece of paper, or, for oral lists, a concept in the mind. The list can do both: it can suggest a unity that relies on a relation between the parts (repetition and variation) and a relationship that only relies on what we have called "unifying gesture," something that creates a whole to which the diverse and entirely disconnected parts stand in relationship with. It can therefore be noted that the prominent features of visual lists are (1) the manifestation of a pattern of repetition in variation and/or (2) the highlighting of the relationship between a whole and its parts. 
Given these characteristics, what is the added value of the concept of the visual list? The answer is twofold. In visual studies, where the term series has become too narrow and specific, it opens a new perspective on enumerative structures in art. Meanwhile, it counteracts the fuzziness of the notion of series in other disciplines (which can signify everything from the scale of nature to television instalments) $)^{30}$ and draws attention to the form of the enumerative, the "made" character of the list.

It is often an artifact's title that creates and draws attention to the productive tension between the parts and the whole. This is the case when numerical values are part of the title. Albrecht Dürer's The Martyrdom of the Ten Thousand Christians (1508) can serve as an example. The discrepancy between the number Ten Thousand mentioned in the title and the number of bodies actually depicted (about sixty) is striking. Eco states that visual lists express their own "incapacity to ... show them all" $(2009,39)$. The list conveys exemplariness: what is represented stands for a larger (social, historical, political) whole, which becomes clear precisely through the formal power of the list to represent an obviously incomplete enumeration. ${ }^{31}$ Hence visual lists afford exemplarity in the sense of exhibiting a selection of details that vary or share a certain theme and which indicate and reference a continuation of that which is shown beyond the frames of the canvas, the paper, or the screen. Visual lists exemplarily refer to events, contexts, and ideas that go beyond what is actually shown.

Last but not least, the reception of certain images as visual lists is a consequence of contextualization in a shared cultural heritage. The Golden Stairs, for example, can be interpreted as making an intermedial reference to the biblical narrative of Jacob's dream of the ladder to heaven as it is described in the book of Genesis (Gen. 28:10-22). ${ }^{32}$ The steering of a specific viewer response and reception through the evocation of certain cultural knowledge and intermedial references should not be underestimated.

To sum up, visual lists can be described by drawing on the following criteria: a vertical or horizontal sequence of similar but usually different and individual (possibly clearly separated and carved out) objects, reminiscent of an enumeration (suggested for example by steps/gradations), which create the effect of repetition in variation. Moreover, less neatly arranged accumulations of individual objects can still be perceived as visual lists if the relationship between a whole and its parts is accentuated in a prominent way. All of these characteristics can be found to a greater or 
lesser extent in the detailed analyses of the individual contributions to Part III of this book.

Agnes Blümer's contribution (Chap. 11) focuses on forms, functions, and processes of knowledge construction in diverse genres of children's literature including children's poetry, folklore, novels, and picturebooks. While Blümer addresses the list's educational and didactic purpose, she also draws attention to the fact that lists in children's literature can deliberately subvert the supposed didactic function: "Their tendency for excess, for puns and for comical effects seems to undermine the traditional educational value of the list form" (Blümer). In her discussion of lists in picturebooks, Blümer highlights the interactive experiences that lists in children's literature often evoke. Picturebooks famously use lists as a tool to "archive the everyday" and to convey the yet unknown to the child. Yet, as "a multi-purpose form" that affords educational, aesthetic, and interactive functions, lists in children's literature do not simply order knowledge, they also subvert it.

In Chap. 12, Daniela Wagner's contribution explores different versions of medieval representations of the Arma Christi, a term that refers to weapons, torture devices, or other objects related to the suffering of Jesus Christ. Since Arma Christi representations are only roughly defined by the context of the Passion narrative, there are various versions that differ both in terms of the selection of elements and regarding their combination and arrangement. These processes of selection and combination highlight the "list-like character" of many Arma representations. For the visual list, as for the verbal list, the tension between "the cohesion of the whole and the separation of the parts" (Wagner) is essential. Wagner shows that it is specifically through innovative uses of framing that the simultaneous demarcation of the individual parts and what she calls "visual merging" becomes possible. As many representations of the Arma give rise to an "interplay of overview and disorder" (Wagner), the viewer is prompted to draw connections between the individual parts (the various Arma) as well as the relationship between the parts and the whole (the body of Christ). As Wagner further shows, it is the specific interaction of content and form that renders the motif of the Arma particularly effective for the practice of piety.

Finally, in Chap. 13, Anja Schürmann turns to the medium of photography. As photography can "freeze time" (Schürmann), the medium is particularly well suited for isolating subjects from their surroundings and putting them into other contexts in which new meanings can be forged. 
By initially anchoring the genre of the conceptual documentary photobook in its serial and conceptual legacy, Schürmann emphasizes both the principle of distancing as well as the principle of repetition as constituting moments of visual lists. As Conceptual Documentary photography typically explores "a single, often banal idea from many different angles" (Miles 2010, 50), repetition and variation inform their visual aesthetics: "Its formal and abstract aspects are reinforced while what is depicted loses relevance" (Schürmann). As she provides an analysis of three contemporary photobooks, Schürmann applies Peter Bexte's considerations on "the etcetera" as a verbal, a visual, and a philosophical form of conceptualization to highlight the synthetic (rather than the analytic) and the open or non-hierarchical structure of the presented art works. The enumerative structure of Conceptual Documentary photobooks, she argues, effects interpretive gaps between the individual images and thus fosters a receptive autonomy which ultimately reacts to and comments on the moralizing tendencies of documentary photography.

Critical readers of Chaps. 11, 12 and 13 will agree that the assertion that there $i$ s such a thing as the visual list will always lead us into problems of definition. Even though plural images or "hyperimages" (Thürlemann 2013) have gained attention in art history and visual studies alike, they have not been described as lists but rather were treated under terms such as series. The media scientist Knut Hicketier, when he experienced the difficulty of demarcating a ubiquitous form (in his case the series), suggested not to assume (or construct) an essential and fixed idea of the concept but rather to follow an inductive approach and to describe it as a product of the recipient's perception. ${ }^{33} \mathrm{~A}$ visual list would then be whatever is perceived as a visual list, that is, what is produced, communicated, received, and processed as such. If we follow this inductive approach, we can begin to focus on the meaningful re-reading of visual artifacts as visual lists and to pay attention to the innovative interpretive contexts and connections this perspective on and framing of the material affords. The term visual list-precisely because of its odd novelty-disturbs and defamilarizes the common categorization of plurality in art as serial or series. The concept of the visual list asks us to realize how arbitrary and vague the notion of series has become and re-focuses attention on the issue of form: how does the aesthetic effect (and maybe also "the message") of a piece of art change when it is read against the background of the formal aesthetics of the list? 
Christiane Frey and David Martyn have suggested that lists challenge us when our attempt to assign them to a common denominator is frustrated: "It is precisely because the category, which would have allowed to subsume the individual items under a general heading and thus to be put aside and done with, is missing, that the individual items can emerge in their detail" (90). ${ }^{34}$ It is this 'putting aside and being done with' that is provoked by titles such as The Martyrdom of the Ten Thousand Christians. By referring to a specified whole, and thus manipulating the reception of the artwork, it reduces the visibility of the individual elements in their respective individuality and peculiarity (see Frey and Martyn 2016, 91). One way to challenge this customary primacy of the whole is to stress a discrepancy between the title and the content of the picture (as Dürer does when he refers to Ten Thousand but only represents sixty). Thus, a certain mismatch is evoked that counteracts the dominance of the whole over the details. To read visual material as a visual list furthers our understanding of the ways in which these works offer resistance to the hierarchical subsumption of particularities under generalizing umbrella terms (see Frey and Martyn 2016, 96). Visual lists ask us to remain specific as they afford the representation of "the plural experience of singularity" (Frey and Martyn $2016,90)^{35}$ and as such oppose generalization. Somewhat paradoxically, the visual list allows us to perceive categories, yet also makes us honor the individual elements.

Together, the twelve contributions to this book highlight the list's striking versatility, its ability to produce scientific, literary, and art work across times and cultures. They provide answers to Jack Goody's (1977) famous question "What's in a list?" in that they point out various affordances of this all but simple textual or visual form. With its interdisciplinary approach, List-Making: Epistemic, Literary, and Visual Enumeration aims to contribute to an emerging field dedicated to the study of lists.

\section{Notes}

1. See Deutsches Wörterbuch von Jacob und Wilhelm Grimm Online, s.v. Liste. See also OED Online, s.v. list, n.3. Both accessed 9 Dec. 2020.

2. The $O E D$ entry (see note 1 ) provides a quote from G. Fletcher's 1591 of Russe Common Wealth to show the longstanding association with the term border: "the very farthest part and list of Europe, bordering vpon Asia."

3. See, for example, the monograph of Greber (2002) and the most recent article on the subject by Hyer (2019). 
4. See, for example, Spufford 1989.

5. For the significance of lists in antiquity, see Goody 1977, Wassermann 2021.

6. In The Analytical Language of John Wilkins (1973, 103), Borges gives expression to the playfulness of lists which, according to Goody (1977, 89 ), is characteristic already for ancient lists. Foucault (1980) begins his The Order of Things by quoting Borges' list.

7. See, for example, Goody (1977) and Hess and Mendelssohn (2010). See also Gitelman's monograph on Paper Knowledge (2014).

8. In a special issue for Society and Space, De Goede et al. (2016) discuss listmaking as a practice of governance that relies on particular ways of knowledge production and world-ordering procedures. Similarly, the sociologist Urs Stäheli $(2011,2016,2017)$ has repeatedly emphasized that list-making is not just an activity to create order in the sense of an overview, but that it also involves invisible power structures which define processes of preselection and arrangement.

9. See, for example, Kühlmann 1973, Visser 1997, Sammons 2010.

10. Schumann $(1942,1944,1945)$ is an exception to the rule. His observation that literary enumeration can be both "conjunctive" and "disjunctive," that is, that it can add items so as to create a whole or, by contrast, itemize a whole into its parts, is crucial. However, his scope is limited to the works of Whitman and German expressionist poets. In French criticism, the pioneering study of Frédéric (1986) comes to a similar conclusion in that it differentiates between énumération homologique and énumération chaotique.

11. This study, though it draws on a selected corpus of mostly canonical texts, aptly discusses the rhetorical as well as the poetological aspects of enumerative writing and points to the frequent self-reflective nature of literary enumeration.

12. See Belknap 2004, Sève 2010, Milcent-Lawson et al. 2013, Turin 2017. An earlier example is Spufford (1989). His The Chatto Book of Cabbages and Kings: Lists in Literature provides an anthology of literary lists.

13. Though it focuses on lists in a particular epoch, Belknap's study also examines lists and catalogues across different genres: the essay, poetry, the novel, and the memoir. Other genre-specific studies of literary enumeration include: Cotten (2008) for lists in concrete poetry; Poletti (2008) for lists in personal zines; Rüggemeier $(2019,2020)$ for lists in life writing and graphic novels. Forthcoming is a study on lists in detective fiction by Sarah Link. A broader genre-based approach to literary list-making is still wanting.

14. See, for example, Young 2017, 12, 109-129.

15. For instance, Eco (2009) develops a vague philosophical concept of listlikeness, which supposedly is characterized by excess and infinity. For 
Young (2017), who discusses ancient Sumerian inventories alongside BuzzFeed listicles, "listing activities are the infrastructure of culture" (19). Eva von Contzen (2017) has taken a more nuanced view and suggested that the versatility of the list, its remarkable sensitivity to historical contexts, is due to potentialities inherent in the form of the list. Drawing on the new formalist study of Levine (2015), she has termed the many potential functions of the list affordances.

16. See Te Heesen 2005, Hess and Mendelssohn 2010, Müller-Wille and Charmantier 2012.

17. Goody (1977) claims that list-making influences cognitive processes, a claim that he explores with respect to lists in ancient Mesopotamia and Egypt. He argues that writing, and list-making especially, impacts human cognition, namely as it allows for the re-arrangement and examination of words or word sequences.

18. This definition harks back to pre-Socratic traditions. For a detailed account of the term's history, see Historisches Wörterbuch der Philosophie, s.v. "Episteme." See also "Episteme and Techne," Stanford Encyclopedia of Philosophy Online, https://plato.stanford.edu/entries/episteme-techne/. Accessed 6 Jan 2021.

19. See Foucault 2002, esp. xxii-xxv. For a precise definition of the term, see Foucault 1980, 197: "If you like, I will define épistème retrospectively as the strategic apparatus which permits the separating out from among all the statements which are possible those that will be acceptable within, I won't say a scientific theory, but a field of scientificity, and which it is possible to say are true or false." For a discussion of Foucault's interpretation of the list by Borges, see Ottmar Ette's chapter in this volume.

20. For Pomata 2010, esp. 196-197, epistemic genres are literary structures that afford specific ways of arranging given material and, thus, allow for certain epistemic endeavors. See also Urmann 2017 (on the epistemic genre of the question) and Pomata 2013 (on the epistemic genres of the case and the recipe).

21. Eco differentiates between the (subjective) aesthetic effect that derives from the idea of infinity, which Kant defines as the sublime in his Critique of Judgement, and so-called "objective" infinity. According to Eco, the latter rather than the former finds expression in the list. See Eco 2009, 17.

22. The list as a classificatory tool with which to divide and subdivide materials, as described by Goody (1977), must be infinite in the perspective of Empiricism. This paradigm shift in the epistemic history of the list no doubt deserves more attention and research than it can receive in this introduction. It is discussed at greater length in Roman Alexander Barton's forthcoming article "Endless Lists in Sprawling Narratives: Enumeration in the Sternean Novel." 
23. See Hess and Mendelsohn (2010), esp. 299: "Running the eye down any given organ column [in the anatomical table of Pierre Charles Alexandre Louis] and keeping the duration in view, one would see in an almost automatically tallying mode what proportion of cases, in each duration range, presented a given range of descriptive terms."

24. See, for example, Peirce, Collected Papers, VIII, 226, where Peirce discusses the lack of an interpretant or "mental element" in dyadic relations, without which there can be no semiosis or sign, properly speaking: "In A's putting away $\mathrm{B}$, there is no thirdness. In C's taking $\mathrm{B}$, there is no thirdness. But if you say that these two acts constitute one single operation by virtue of the identity of the B, you transcend the mere brute fact, you introduce a mental element."

25. See Mainberger (2020), who engages with the table of contents as a visual phenomenon.

26. The belief that stable constructs of meaning ("grand narratives") can exist on a large scale is explored in Jean-François Lyotard's The Postmodern Condition: A Report on Knowledge (2006).

27. See also Mainberger who regards the shopping list as the prototype of the list: "If we ask what a Liste is, everyone will most certainly give the shopping list as an example" $(2020,9)$.

28. For a consideration and first remarks on the differentiation between verbal and visual lists, see Rüggemeier 2018, 56.

29. See Deleuze (1994), who defined variation as the condition of repetition. Derrida also connected the notion of repetition with variation ("Signature Event Context," 1988).

30. See Historisches Wörterbuch der Philosophie, s.v. "Series."

31. For a consideration of the list as a reduced and reducing form that highlights the tension between the things mentioned (shown) and the things not mentioned (not shown) see Rüggemeier 2019.

32. Art critics have repeatedly emphasized the dream-like quality of BurnJones's picture. See Wildman and Christian 1998.

33. "Serie ist, was als Serie verstanden, d.h. als solche produziert, vermittelt, rezipiert und verarbeitet wird" (Hicketier 1991, 8).

34. Translation of the German original: "Gerade weil die Rubrik fehlt, die es erlaubt hätte, sie (die Einzeldinge) unter ein Allgemeines zu subsumieren und dadurch gleichsam ad acta zu legen, können sie in ihrer Einzelheit hervortreten" (Frey and Martyn 2016, 90).

35. See also Deleuze on the distinction between generalization (where something can be substituted with something else) and repetition which stands in relation to "something unique or singular which has no equal or equivalent” $(1994,1-2)$. 


\section{REFERENCES}

Belknap, Robert. 2004. The List: The Uses and Pleasures of Cataloguing. New Haven: Yale University Press.

Borges, Jorge L. 1973. The Analytical Language of John Wilkins. In Other Inquisitions 1937-1952 By Jorge Luis Borges, 101-105. Trans. R.L.C. Simms. London: Souvenir Press.

Cotten, Ann. 2008. Nach der Welt: Die Listen der Konkreten Poesie und ibre Folgen. Vienna: Klever.

Deleuze, Gilles. 1994. Difference and Repetition. Trans. Paul Patton. New York: Columbia University Press.

Derrida, Jacques. 1988. Signature Event Context. In Limited Inc. Trans. Samuel Weber and Jeffrey Mehlmann. Evanstone: Northwestern University Press.

Doležalová, Lucie, ed. 2009. The Charm of a List: from the Sumerians to Computerised Data Processing. Newcastle upon Tyne: Cambridge Scholars Publishing.

Eco, Umberto. 2009. The Infinity of Lists. New York: Rizzoli.

Fludernik, Monika. 2016. Descriptive Lists and List Descriptions. Style 50 (3): 309-326.

Foucault, Michel. 1980. Power/Knowledge. Ed. Colin Gordon. New York: Pantheon Books.

- 2002. The Order of Things. London/New York: Palgrave.

Frédéric, Madeleine. 1986. Enumération, énumération homologique, énumération chaotique: Essai de caractérisation. In Stylistique, rhétorique et poétique dans les langues romanes, ed. Jean-Claude Bouvier, 103-117. Provence: Université de Provence.

Frey, Christiane, and David Martyn. 2016. Listenwissen: Zu einer Poetik des Seriellen. In Noch einmal anders. Zu einer Poetik des Seriellen, ed. Elisabeth Bronfen, Christiane Frey and David Martyn, 89-103. Zürich/Berlin: diaphanes.

Gitelman, Lisa. 2014. Paper Knowledge. Durham/London: Duke University Press.

De Goede, Marieke, et al. 2016. Introduction: The Politics of the List. Environment and Planning D: Society and Space 34 (1): 3-13.

Goody, Jack. 1977. The Domestication of the Savage Mind. Cambridge: Cambridge University Press.

Greber, Erika. 2002. Textile Texte: Poetologische Metaphorik und Literaturtheorie Studien zur Tradition des Wortflechtens und der Kombinatorik. Cologne/ Weimar/Vienna: Böhlau.

Te Heesen, Anke. 2005. Accounting for the Natural World: Double-Entry Bookkeeping in the Field. In Colonial Botany. Science, Commerce, and Politics in the Early Modern World, ed. Londa Schiebinger and Claudia Swan, 237-251. Philadelphia: University of Pennsylvania Press. 
Hess, Volker, and J. Andrew Mendelssohn. 2010. Case and Series: Medical Knowledge and Paper Technology, 1600-1900. History of Science 48 $(3 / 4): 287-314$.

Hicketier, Knut. 1991. Die Fernsehserie und das Serielle des Fernsehens. Lüneburg: Kultur-Medien-Kommunikation.

Hyer, Maren Clegg. 2019. Text/Textile: "Wordweaving" in the Literature of Anglo-Saxon England. Medieval Clothing and Textiles 15: 33-51. https://doi. org/10.2307/j.ctvb4bvnq.8. Accessed 6 Jan 2021.

Kühlmann, Wilhelm. 1973. Katalog und Erzäblung: Studien zu Konstanz und Wandel einer literarischen Form in der antiken Epik. PhD dissertation, University of Freiburg.

Levine, Caroline. 2015. Forms: Whole, Rhythm, Hierarchy, Network. Princeton: Princeton University Press.

Lyotard, Jean-François. 2006. The Postmodern Condition: A Report on Knowledge. Minneapolis: University of Minnesota Press.

Mainberger, Sabine. 2003. Die Kunst des Aufzüblens: Elemente zu einer Poetik des Enumerativen. Berlin/Boston: de Gruyter.

. 2020. A List Is (Not) a List: Some (Non-Conclusive) Remarks on Lists and Literature. lwu: Literatur in Wissenschaft und Unterricht. Theme Issue: Lists and Narrative 1 (2): 9-21.

- 2020. Musing About a Table of Contents: Some Theoretical Questions Concerning Lists and Catalogues. In Lists and Catalogues in Ancient Literature and Beyond, ed. Rebecca Laemmle et al., 19-34. Berlin/Boston: de Gruyter.

Milcent-Lawson, Sophie, Michelle Lecolle, and Raymond Michel, eds. 2013. Liste et effet liste en littérature. Paris: Classiques Garnier.

Miles, Melissa. 2010. The Drive to Archive: Conceptual Documentary Photobook Design. Photographies 3 (1): 49-68. https://doi. org/10.1080/17540760903561108. Accessed 6 Jan 2021.

Müller-Wille, Staffan, and Isabelle Charmantier. 2012. Lists as Research Technologies. Isis 103: 743-752.

Poletti, Anna. 2008. Where the Popular Meets the Mundane: The Use of Lists in Personal Zines. Canadian Review of American Studies 38 (3): 333-349.

Pomata, Gianna. 2010. Sharing Cases: The Observationes in Early Modern Medicine. Early Science and Medicine 15 (3): 193-236.

- 2013. The Recipe and the Case: Epistemic Genres and the Dynamics of Cognitive Practices. In Wissenschaftsgeschichte und Geschichte des Wissens im Dialog - Connecting Science and Knowledge, ed. Kaspar von Greyerz, Silvia Flubacher, and Philipp Senn, 131-154. Göttingen: Vanderhoeck \& Ruprecht.

Richardson, Brian. 2016. Modern Fiction, the Poetics of Lists, and the Boundaries of Narrative. Style 50 (3): 327-341.

Rüggemeier, Anne. 2018. The List as a Means of Assessment and Standardization and Its Critical Remediation in Graphic Narratives About Illness and Care. Closure 5: 55-85. 
2019. Lists in Life Writing: The List as a Means to Visualize the Trace of the Absent. a/b Auto/Biography Studies 34 (2): 329-341.

- 2020. Life Writing and the Poetics of List-Making: On the Manifestations, Effects, and Possible Uses of Lists in Life Writing. $a / b$ Auto/Biography Studies 35 (3). https://doi.org/10.1080/08989575.2020.1815371. Accessed 6 Jan 2021.

Sammons, Benjamin. 2010. The Art and Rhetoric of Homeric Catalogue. Oxford/ New York: Oxford University Press.

Schöpsdau, Klaus. 1994. Enumeratio. In Historisches Wörterbuch der Rhetorik, vol. 2, ed. Gert Ueding. Tübingen: Max Niemeyer Verlag. https://db.degruyter. com/view/HWRO/ enumeratio. Accessed 6 Jan 2021.

Schumann, Detlev W. 1942. Enumerative Style and Its Significance in Whitman, Rilke, Werfel. Modern Language Quarterly. 3 (2): 171-204.

- 1944. Observations on Enumerative Style in Modern German Poetry. Publications of the Modern Language Association of America 59 (4): 1111-1155.

- 1945. Conjunctive and Disjunctive Enumeration in Recent German Poetry. Publications of the Modern Language Association of America 60 (2): 517-566.

Sève, Bernard. 2010. De haut en bas. Philosophie des listes. Paris: Seuil.

Spufford, Francis, ed. 1989. The Chatto Book of Cabbages and Kings: Lists in Literature. London: Chatto and Windus.

Stäheli, Urs. 2011. Das Soziale als Liste: Zur Epistemologie der ANT. In Die Wiederkehr der Dinge, ed. Friedrich Balke, Maria Muhle, and Antonia von Schöning, 83-101. Berlin: Kulturverlag Kadmos Berlin.

- 2016. Indexing - The Politics of Invisibility. Environment and Planning D: Society and Space 34 (1): 14-29.

- 2017. Traveling by Lists: Navigational Knowledge and Tourism. Zeitschrift für Literaturwissenschaft und Linguistik 47: 361-374.

Thürlemann, Felix. 2013. Mehr als ein Bild: Für eine Kunstgeschichte des 'hyperimage'. Munich: Wilhelm Fink Verlag.

Turin, Gaspard. 2017. Poétique et usages de la liste littéraire: Le Clézio, Modiano, Perec. Genève: Droz.

Visser, Edzard. 1997. Homers Katalog der Schiffe. Stuttgart: Teubner.

von Contzen, Eva. 2016. The Limits of Narration: Lists and Literary History. Style 50 (3): 24l-26l.

von Contzen, Eva. 2017. Die Affordanzen der Liste. Zeitschrift für Literaturwissenschaft und Linguistik 3: 317-26.

Wassermann, Nathan. 2021. Lists and Chains: Enumeration in Akkadian Literary Texts (with an Appendix on This Device in Borges and Hughes). In Lists and Catalogues in Ancient Literature and Beyond: Towards a Poetics of Enumeration, ed. Rebecca Laemmle et al., 57-80. Berlin/Boston: de Gruyter. 
Wildman, Stephen, and John Christian. 1998. Edward Burne-Jones: Victorian Artist-Dreamer. New York: The Metropolitan Museum of Art.

Young, Liam Cole. 2017. List Cultures: Knowledge and Poetics from Mesopotamia to BuzzFeed. Amsterdam: Amsterdam University Press.

Open Access This chapter is licensed under the terms of the Creative Commons Attribution 4.0 International License (http://creativecommons.org/licenses/ by $/ 4.0 /$ ), which permits use, sharing, adaptation, distribution and reproduction in any medium or format, as long as you give appropriate credit to the original author(s) and the source, provide a link to the Creative Commons licence and indicate if changes were made.

The images or other third party material in this chapter are included in the chapter's Creative Commons licence, unless indicated otherwise in a credit line to the material. If material is not included in the chapter's Creative Commons licence and your intended use is not permitted by statutory regulation or exceeds the permitted use, you will need to obtain permission directly from the copyright holder.

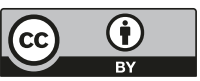

